\title{
BMJ Open Persistence with dual antiplatelet therapy after percutaneous coronary intervention for ST-segment elevation acute coronary syndrome: a population- based cohort study in Catalonia (Spain)
}

To cite: Ribera A, FerreiraGonzalez I, Marsal JR, et al. Persistence with dual antiplatelet therapy after percutaneous coronary intervention for ST-segment elevation acute coronary syndrome: a populationbased cohort study in Catalonia (Spain). BMJ Open 2019;9:e028114. doi:10.1136/ bmjopen-2018-028114

- Prepublication history and additional material for this paper are available online. To view please visit the journal (http:// dx.doi.org/10.1136/bmjopen2018-028114).

Received 26 November 2018 Revised 19 June 2019 Accepted 2 July 2019

Check for updates

(c) Author(s) (or their employer(s)) 2019. Re-use permitted under CC BY-NC. No commercial re-use. See rights and permissions. Published by BMJ.

For numbered affiliations see end of article.

Correspondence to Dr Ignacio Ferreira-Gonzalez; nachoferreira@secardiologia.es

\section{ABSTRACT}

Objectives Guidelines recommending 12-month dual antiplatelet therapy (DAPT) in patients with STelevation acute coronary syndrome (STEACS) undergoing percutaneous coronary intervention (PCl) were published in year 2012. We aimed to describe the influence of guideline implementation on the trend in 12-month persistence with DAPT between 2010 and 2015 and to evaluate its relationship with DAPT duration regimens recommended at discharge from PCI hospitals.

Design Observational study based on region-wide registry data linked to pharmacy billing data for DAPT follow-up.

Setting All PCI hospitals (10) belonging to the acute myocardial infarction (AMI) code network in Catalonia (Spain).

Participants 10711 STEACS patients undergoing PCl between 2010 and 2015 were followed up.

Primary and secondary outcome measures Primary outcome was 12-month persistence with DAPT. Calendar year quarter, publication of guidelines, DAPT duration regimen recommended in the hospital discharge report, baseline patient characteristics and significant interactions were included in mixed-effects logistic regression based interrupted time-series models.

Results The proportion of patients on-DAPT at 12 months increased from $58 \%(56-60)$ in 2010 to $73 \%$ (71-75) in 2015. The rate of 12-month persistence with DAPT significantly increased after the publication of clinical guidelines with a time lag of 1 year $(\mathrm{OR}=1.20 ; 95 \% \mathrm{Cl} 1.11$ to 1.30). A higher risk profile, more extensive and complex coronary disease, use of drug-eluting stents $(\mathrm{OR}=1.90$; $95 \% \mathrm{Cl} 1.50$ to 2.40 ) and a 12-month DAPT regimen recommendation at discharge from the $\mathrm{PCl}$ hospital $(0 \mathrm{R}=5.76 ; 95 \% \mathrm{Cl} 3.26$ to 10.2$)$ were associated with 12-month persistence.

Conclusion Persistence with 12-month DAPT has increased since publication of clinical guidelines. Even though most patients were discharged on DAPT, only $73 \%$ with potential indication were on-DAPT 12 months after
Strengths and limitations of this study

- The study describes the trends in persistence with dual antiplatelet therapy (DAPT) during 2010-2015 in a region-wide comprehensive cohort of patients using administrative data linked to a clinical registry.

- It also evaluates the impact of the DAPT duration recommended at the percutaneous coronary intervention hospital discharge on 12-month persistence.

- Limitations of using observational registry data include the possibility of coding errors and the inability to accurately identify specific contraindications for treatment or other patient characteristics that might be relevant for the study aims.

- The use of pharmacy refill data as a proxy of patients' adherence and persistence has also limitations which have been extensively described.

$\mathrm{PCl}$. A guideline-based recommendation at $\mathrm{PCl}$ hospital discharge was highly associated with full persistence with DAPT. Establishing evidence-based, common prescribing criteria across hospitals in the AMI-network would favour adherence and reduce variability.

\section{INTRODUCTION}

The need of dual antiplatelet therapy (DAPT) combining aspirin and an ADP-receptor blocker for at least 12 months in patients with ST-elevation acute coronary syndrome (STEACS) undergoing percutaneous coronary intervention (PCI) is well established and was incorporated into clinical guidelines in 2012. ${ }^{12}$

Adherence of patients to this strategy is crucial to ensure its efficacy. Adherence to 
medication is usually defined ${ }^{3}$ as the extent to which patients take medications as prescribed by their healthcare providers and persistence is defined as time from initiation to discontinuation of a therapy. Patients' persistence with DAPT may be influenced by several factors but will depend strongly on whether they ultimately receive a correct prescription from their physicians in the primary care setting. Patients may receive recommendations from various health providers at different stages of their process of care, from the interventionist cardiologist to their primary physician. It could be hypothesised that the last would tend to rely on the recommendation of the more specialised health professional. Thus, one potential determinant of patients' persistence with DAPT for at least 12 months is the instructions provided in the discharge report of the hospital where the patient was attended during the acute phase.

In Catalonia, an autonomous region of Spain, the acute care of STEACS is organised through a region-wide network, the acute myocardial infarction (AMI) code, to derive patients with suspected STEACS to 1 of the 10 reference hospitals with PCI capability. Performance of the AMI code is prospectively and exhaustively registered, ${ }^{45}$ providing an appropriate tool for quality evaluation. The Catalan Health Information System systematically registers, among other, data on pharmacy refills. Pharmacy billing data, although indirect, is an accepted method for evaluating persistence with treatment in large patient cohorts. ${ }^{36}$

The aims of the present study were, first, to describe persistence with DAPT for at least 12 months in patients with STEACS undergoing PCI from 2010 to 2015; second, to evaluate the influence guidelines recommendation for a 12-month DAPT schedule on the rate of 12-month persistence along time; and third, to evaluate the association of the DAPT duration recommended at the PCI hospital discharge with patients' persistence with treatment for at least 12 months.

\section{METHODS}

\section{Data sources}

Data were obtained through the Public Data Analysis for Health Research and Innovation Programme (PADRIS). The PADRIS allows access to information from different sources on public healthcare resources usage for the population of Catalonia linked at the patient level with warranted accomplishment of ethical principles. Specifically, for the present study we linked data of the pharmacy billing registry with the AMI code registry. The AMI code registry was launched in 2010 to evaluate performance of the AMI code. ${ }^{45}$ Exhaustiveness and quality of data are assessed periodically (see online supplementary methods for details). The database belongs to the Catalan Department of Health and includes demographic, clinical and therapeutic data for each episode of hospitalisation for STEACS. It conforms to the ethical and legal requirements for research purposes.
The registry was completed for the purpose of the present analysis with retrospective collection of additional specific data: diseased vessels, responsible vessel, stent type and number of stents. The recommendation of antithrombotic drugs was also collected ad hoc for the study from the discharge report. The recommendation of DAPT was defined as the recommendation of acetylsalisilic acid (ASA) and clopidogrel, prasugrel or ticagrelor for specified periods. If the recommended duration of DAPT was not specified, the discharge recommendation pattern was classified as 'unspecified'. A local investigator at each centre performed the specific retrospective data collection.

History of major haemorrhage, neoplasia, renal disease, heart failure, peripheral arterial disease and atrial fibrillation, were obtained from minimum basic data set diagnoses coded in hospitalisation episodes occurring in the previous 3 months before index hospitalisation. Major haemorrhage was defined as: a diagnosis of digestive bleeding in any diagnostic position (primary or secondary) together with a procedure code for endoscopic treatment or for transfusion of blood products, or a diagnosis of haemorrhagic stroke, or a diagnosis of intraocular haemorrhage, or a diagnosis of other types of haemorrhage together with a procedure code for transfusion of blood products. Major ischaemic events (AMI or stroke) and major haemorrhage during the 12 months following the index episode were obtained in the same way. Mortality during the 12 months following the index episode was obtained from the insured registry status.

Drug treatment during the 12-month postdischarge follow-up was obtained from the pharmacy billing registry. International Classification of Diseases, Ninth Revision, Clinical Modification (ICD-9-MC) and ATC codes used for the identification of study variables are listed in the online supplementary tables 1 and 2.

\section{Data availability statement}

Additional data are not available due to ethical requirements of the PADRIS.

\section{Study population}

We included all consecutive patients who survived a STEACS between January 2010 and December 2015, received primary or postfibrinolysis PCI in 1 of the 10 reference hospitals of the AMI code network, were discharged home or transferred to another hospital and survived at least 1 month after AMI. New episodes of STEACS occurring to the same patients during the study period were only accounted as follow-up events. Patients with likely contraindication for DAPT (history of major bleeding or neoplasm in the 3 months prior to the index episode and patients requiring anticoagulation) were excluded.

\section{Persistence with treatment}

DAPT was defined as the concomitant use of ASA and a $\mathrm{P}_{2} \mathrm{Y}_{12}$ antagonist. Persistence with DAPT was estimated by 
identification of consecutive months with pharmacy refills with one container of each agent in the 12-month period after hospital discharge. Because pharmacy billing is registered in a monthly basis and the exact day of dispensation is unknown, we considered that a monthly dispensation until at least month 11 after the index episode would approximate a 12-month treatment period. If more than one container were dispensed in 1 month, the excess containers were pulled along the following months. Non-persistence was defined as either discontinuation or a break in therapy of at least 2 months after pulling along the excess containers. To describe persistence over the whole study period, we estimated the proportion of patients alive and within the 12 months after discharge window who were on treatment on each month. ${ }^{7}$

The primary outcome was a patient's persistence with DAPT for 12 months following discharge (or in other words, patients withdrawing both agents from the pharmacy until at least month 11).

\section{Statistical analysis}

We compared baseline characteristics between patients persisting with DAPT for at least 12 months and patients withdrawing DAPT before 12 months with $\chi^{2}$ test or t-test when appropriate. We tested for trends in patients' characteristics along calendar year of discharge for the index procedure with Jonckheere-Terpstra test for differences between ordered categories.

To evaluate the influence of time, guidelines publication and the DAPT duration recommended in the PCI hospital discharge report, we modelled logistic regression based interrupted time-series analysis, ${ }^{8}$ adjusting for baseline characteristics. As a first step, because it is expected that guidelines publication influences practice with a time delay, we plotted the proportion of patients persisting on-DAPT for 12 months by year quarter of discharge from the PCI hospital and we tested models with a slope change (indicating the start of guideline implementation) at different lag periods after publication of the European clinical guidelines (last quarter of 2012). Once the lag period between guidelines publication and implementation of recommendations was estimated, we included patient characteristics and second or third level interactions of each characteristic with year quarter and moment of implementation. We also included an autocorrelation term. We coded time $(T)$ as the time elapsed since the publication of guidelines plus the lag period (in quarters) and a dummy variable $\left(X_{t}\right)$ indicating the preimplementation period (coded 0 ) or the postimplementation period (coded 1$){ }^{9}$

The standard model specification was the following:

$$
\operatorname{logit}\left(Y_{t}\right)=\beta_{0}+\beta_{1} T+\beta_{2} X_{t}+\beta_{3} T X_{t}
$$

Where $\beta_{0}$ represents the baseline level at $T=0, \beta_{1}$ is interpreted as the change in outcome associated with a time unit (quarter) increase (representing the underlying preimplementation trend), $\beta_{2}$ is the level change following the implementation and $\beta_{3}$ indicates the slope change following the implementation (using the interaction between time and implementation: $T X_{t}$ ). Additional terms can be added to model the effect of other covariables and their interactions with $T$ and $X_{t}$ and to include random effects. Note that we set $T=0$ at the quarter where we observed a significant change in the slope at a lag time after guidelines publication.

We took into account the clustered structure of data with patients being treated and, most importantly, with recommendations on DAPT duration being provided in different hospitals, by introducing random effects in the logistic regression models.

We tested whether models including random intercepts for hospital and random slopes for each independent variable were significant using a deviance-based test of hypothesis.

Variable selection for multilevel modelling was based on the bivariate associations with the rate of each dependent variable. Candidate individual variables were those described in tables 1 and 2. We retained in the final model all variables with a $\mathrm{p}$ value $<0.2$.

Plots of predicted probability values were used to show marginal effects of variables of interest and variability between centres.

\section{Sensitivity analyses}

Because a substantial proportion of patients were returned to their reference hospital and because it was unknown whether the DAPT duration recommendation was changed at discharge from the second hospital, we performed sensitivity analyses excluding these patients. Additionally, because ischaemic and haemorrhagic events occurring during follow-up would change the treatment length, sensitivity analyses were also performed by excluding patients suffering any vascular event during follow-up.

\section{Patient and public involvement}

Neither patients nor public were directly involved in the study.

\section{RESULTS}

After excluding patients with likely contraindication for DAPT (figure 1), we identified 10711 STEACS patients undergoing PCI who were potential candidates to receive DAPT for at least 12 months and survived for at least 1 month after discharge. Six hundred and thirty-one $(5.9 \%)$ patients experienced an ischaemic major event (AMI or stroke) within 12 months after the index episode, $100(0.9 \%)$ had a major haemorrhage and 280 (2.6\%) died between 1 and 12 months after the index episode. After excluding patients who died or were lost to follow-up and patients with errors in quarter allocations, 10262 patients remained for analysis.

Table 1 shows characteristics of study patients depending on persistence with DAPT. Patients persisting 
Table 1 Characteristics of study patients according to DAPT persistence during follow-up

\begin{tabular}{|c|c|c|c|c|c|c|c|}
\hline & \multicolumn{2}{|c|}{$\begin{array}{l}\text { DAPT <12 months } \\
(n=3684)\end{array}$} & \multicolumn{2}{|c|}{$\begin{array}{l}\text { DAPT } \geq 12 \text { months } \\
(n=6578)\end{array}$} & \multicolumn{2}{|c|}{$\begin{array}{l}\text { Total } \\
(n=10262)\end{array}$} & \multirow[b]{2}{*}{$P$ value } \\
\hline & $\mathbf{N}$ & n (\%) & $\mathbf{N}$ & n (\%) & $\mathbf{N}$ & n (\%) & \\
\hline Gender (female) & 3684 & $765(20.8 \%)$ & 6578 & $1319(20.1 \%)$ & 10262 & $2084(20.3 \%)$ & 0.399 \\
\hline Smoke $(Y)$ & 3684 & $1774(48.2 \%)$ & 6578 & $3042(46.2 \%)$ & 10262 & $4816(46.9 \%)$ & 0.064 \\
\hline Hypertension (Y) & 3684 & $1622(44 \%)$ & 6578 & $3142(47.8 \%)$ & 10262 & $4764(46.4 \%)$ & $<0.001$ \\
\hline Hypercholesterolaemia (Y) & 3684 & $1291(35 \%)$ & 6578 & $2678(40.7 \%)$ & 10262 & 3969 (38.7\%) & $<0.001$ \\
\hline Polyvascular disease $(\mathrm{Y})^{*}$ & 3684 & $530(14.4 \%)$ & 6578 & 1048 (15.9\%) & 10262 & $1578(15.4 \%)$ & 0.038 \\
\hline Previous stroke or transient ischaemic attack $(\mathrm{Y})$ & 3684 & $101(2.7 \%)$ & 6578 & $172(2.6 \%)$ & 10262 & $273(2.7 \%)$ & 0.704 \\
\hline Previous acute myocardial infarction (Y) & 3684 & $265(7.2 \%)$ & 6578 & $570(8.7 \%)$ & 10262 & $835(8.1 \%)$ & 0.010 \\
\hline Hepatopathy $(Y)$ & 3684 & $48(1.3 \%)$ & 6578 & $56(0.9 \%)$ & 10262 & $104(1 \%)$ & 0.030 \\
\hline History of renal impairment $(Y)$ & 3684 & $185(5 \%)$ & 6578 & $320(4.9 \%)$ & 10262 & $505(4.9 \%)$ & 0.741 \\
\hline History of heart failure $(Y)$ & 3684 & $272(7.4 \%)$ & 6578 & $583(8.9 \%)$ & 10262 & $855(8.3 \%)$ & 0.009 \\
\hline Affected number of vessels $\geq 2(Y)$ & 3684 & $1275(34.6 \%)$ & 6578 & $2731(41.5 \%)$ & 10262 & $4006(39 \%)$ & $<0.001$ \\
\hline No of treated vessels & 3613 & $1.03 \pm 0.21$ & 6516 & $1.06 \pm 0.26$ & 10129 & $1.05 \pm 0.25$ & $<0.001$ \\
\hline No of stents & 3681 & $1.09 \pm 0.6$ & 6563 & $1.21 \pm 0.68$ & 10244 & $1.16 \pm 0.65$ & $<0.001$ \\
\hline Drug-eluting stent $(\mathrm{Y})$ & 3684 & $572(15.5 \%)$ & 6578 & $2704(41.1 \%)$ & 10262 & $3276(31.9 \%)$ & $<0.001$ \\
\hline DAPT score points & 3684 & $1.20 \pm 1.20$ & 6578 & $1.28 \pm 1.17$ & 10262 & $1.25 \pm 1.18$ & $<0.001$ \\
\hline Discharged home $(\mathrm{Y})$ & 3684 & $2233(60.6 \%)$ & 6578 & $3672(55.8 \%)$ & 10262 & 5905 (57.5\%) & $<0.001$ \\
\hline 1 month & & $875(23.8 \%)$ & & 295 (4.5\%) & & $1170(11.4 \%)$ & \\
\hline$<12$ months & & $385(10.5 \%)$ & & $173(2.6 \%)$ & & $558(5.4 \%)$ & \\
\hline$\geq 12$ months & & $1522(41.3 \%)$ & & 4732 (71.9\%) & & $6254(60.9 \%)$ & \\
\hline Unknown & & $902(24.5 \%)$ & & $1378(20.9 \%)$ & & $2280(22.2 \%)$ & \\
\hline
\end{tabular}

*Polyvascular disease was defined as presence of at least two of the following conditions: previous myocardial infarction or percutaneous coronary or surgical revascularisation; history of peripheral arteriophaty; history of stroke or transient ischaemic attack.

†Comorbidity was defined as presence of one of the following conditions: hepatophaty, history of renal impairment, history of heart failure. DAPT, dual antiplatelet therapy.

for at least 12 months had higher prevalence of cardiovascular risk factors (hypertension, diabetes and hypercholesterolaemia), higher rate of a previous history of cardiovascular disease, more extended coronary disease, higher rate of drug-eluting stents implantation and slightly higher ischaemic risk (as measured with the DAPT score ${ }^{10}$ ). Persisting patients were more often transferred to their reference hospital and had had a prescription for a longer DAPT period at discharge from the PCI hospital.

The rate of patients on-DAPT after discharge from the PCI hospital was $91 \%$ (95\% CI 90 to 91) without relevant differences between years (online supplementary figure
1). The proportion of patients on-DAPT at 12 months significantly increased from 58\% (56-61) in 2010 to $73 \%(71-75)$ in 2015 . The larger increase in 12-month persistence was observed between 2014 (64\% (62-66)) and 2015, 2 years after the publication of clinical guidelines. The proportion of patients with prasugrel or ticagrelor instead of clopidogrel started increasing after 2012 (online supplementary figure 2).

Some baseline characteristics showed a temporal trend over the study period 2010-2015 (table 2). The prevalence of cardiovascular risk factors (smoking, hypertension and hypercholesterolaemia) and comorbidities increased slightly. Likewise, the number of treated vessels 


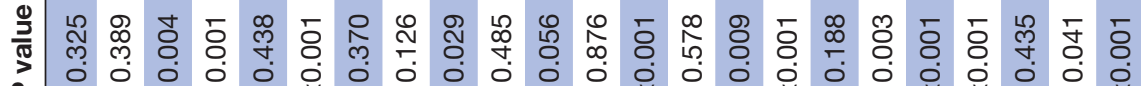
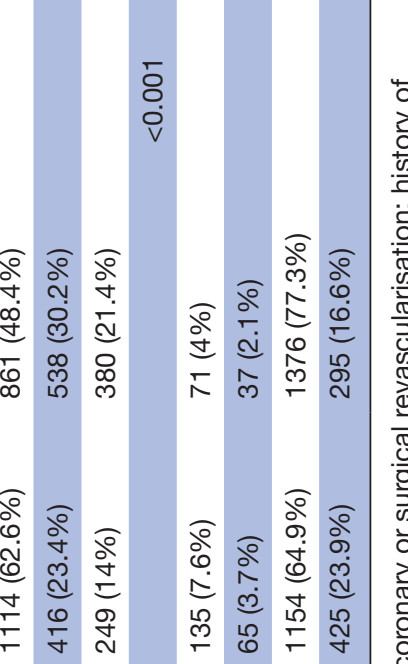

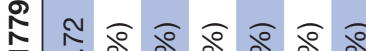

元

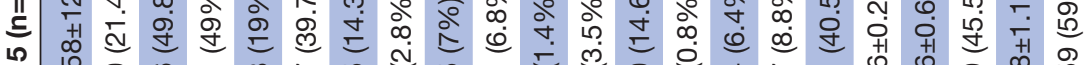

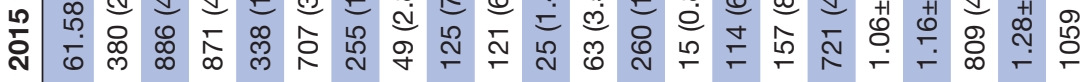

过 ठे

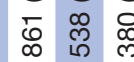

蕰

i.

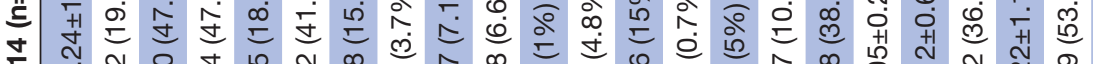

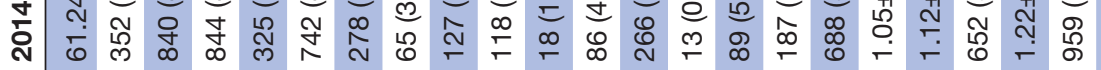

๕̊ำ

ฮู่

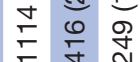

ल

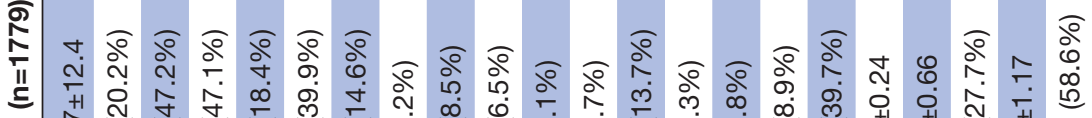

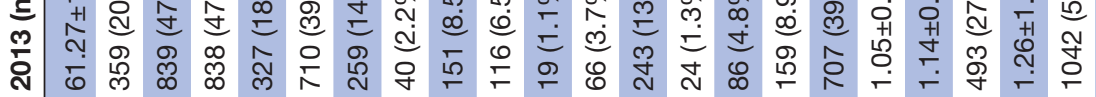

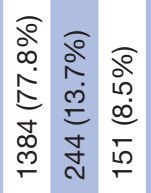

ठิ

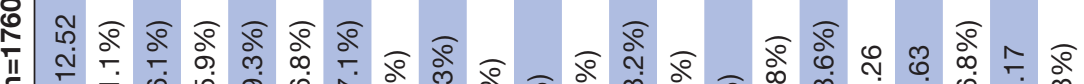

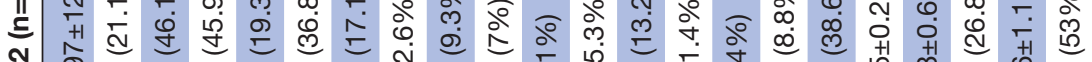

స̌

कें

வ্ণ

空

๙ัฒ

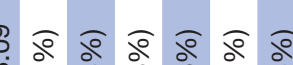

$\times$ II

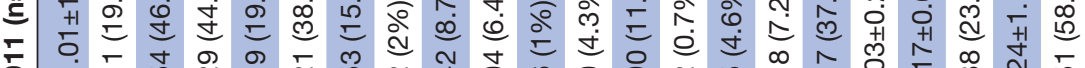

১ิ?

बे के वे

范

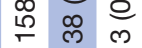

बे

- $\overline{0} \overline{0}$

भे

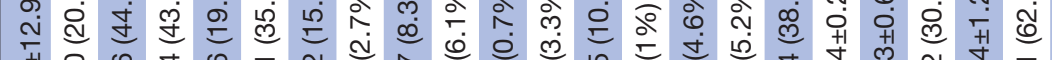

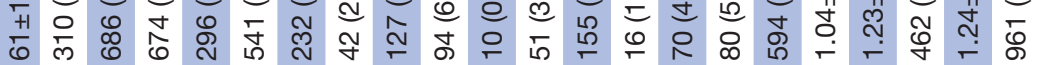

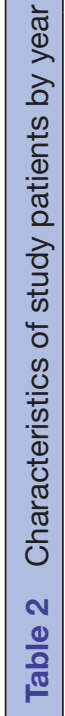

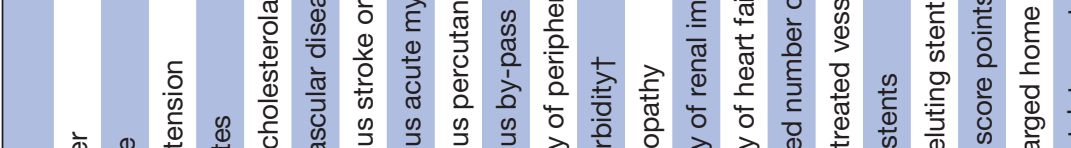

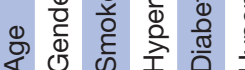

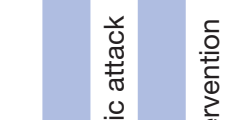

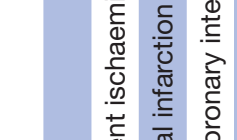

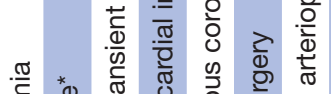

है

西

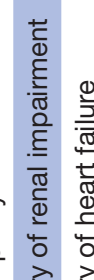

N

$\frac{\infty}{0}$

\$

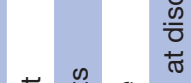

ᄋे वे

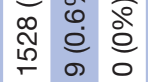

วิ

กิ वे वे

ऽ
을 बें

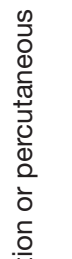

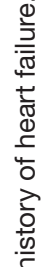

$\widehat{\circ} \widehat{\circ} \bar{\circ}$

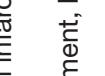

它定

旁 으 ᄂ

잉

हे बूँ

응

㐫

वे के

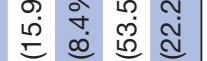

命

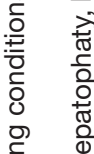

实

a $\widehat{a}$

음 $\stackrel{\ddot{\circ}}{\circ}$

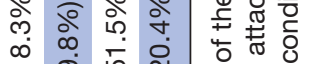

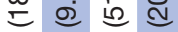

을

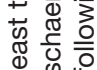

त.

क $\frac{\omega}{\omega} \frac{\pi}{0}$

过

ه

文造

政娄

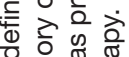

की

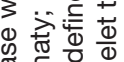

ه 응 of

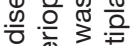

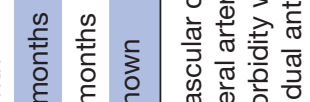

증은 능

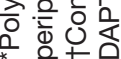




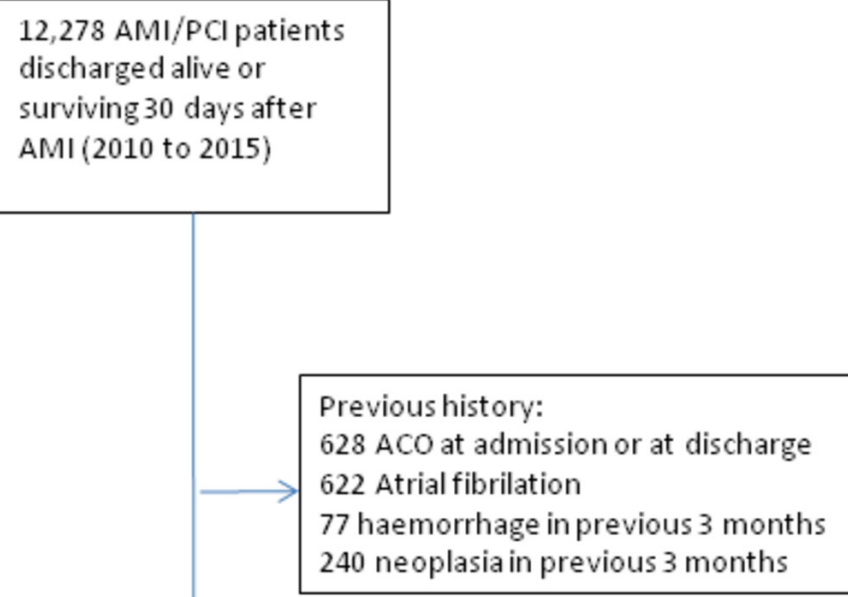

10,711 patients with potential indication for DAPT for at least 12 months

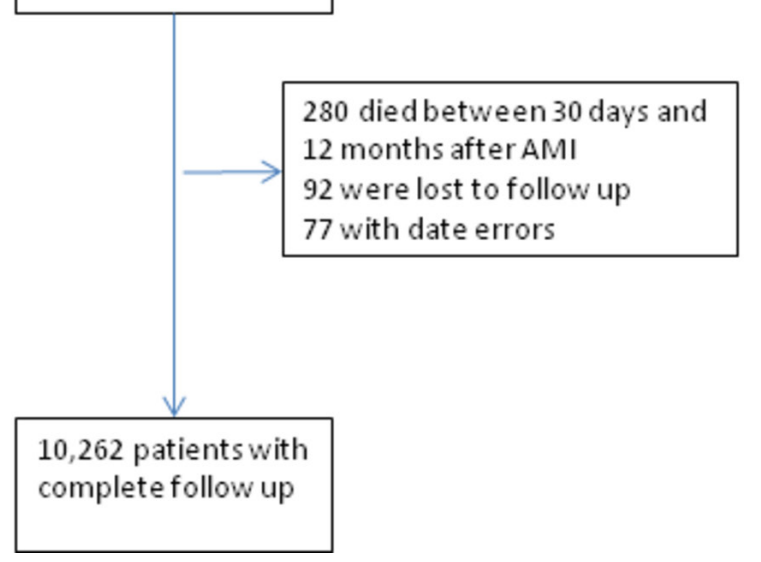

Figure 1 Patients flow. AMI, acute myocardial infarction; DAPT, dual antiplatelet therapy; $\mathrm{PCl}$, percutaneous coronary intervention; ACO, anticoagulant therapy.

the rate of drug-eluting stents implantation and the rate of prasugrel or ticagrelor also increased with time.

The overall rate of explicit DAPT recommendation for at least 12 months in the hospital discharge reports was $51 \%(49-53)$ in 2010 and increased to $77 \%(75-79)$ in 2015 but it was highly variable between hospitals (online supplementary figure 3 ).

Figure 2 shows the observed proportion of patients persisting with DAPT for at least 12 months at each time point and the interrupted time series model fitted after setting a 1 year lag period from publication to implementation of guidelines.

Table 3 shows results of the complete cases analysis $(n=10244)$ using interrupted time series logistic regression. Variables showing association with 12-month persistence on DAPT were two or more diseased vessels, higher number of stents implanted, receiving drugeluting stents, hypercholesterolaemia, a previous surgical

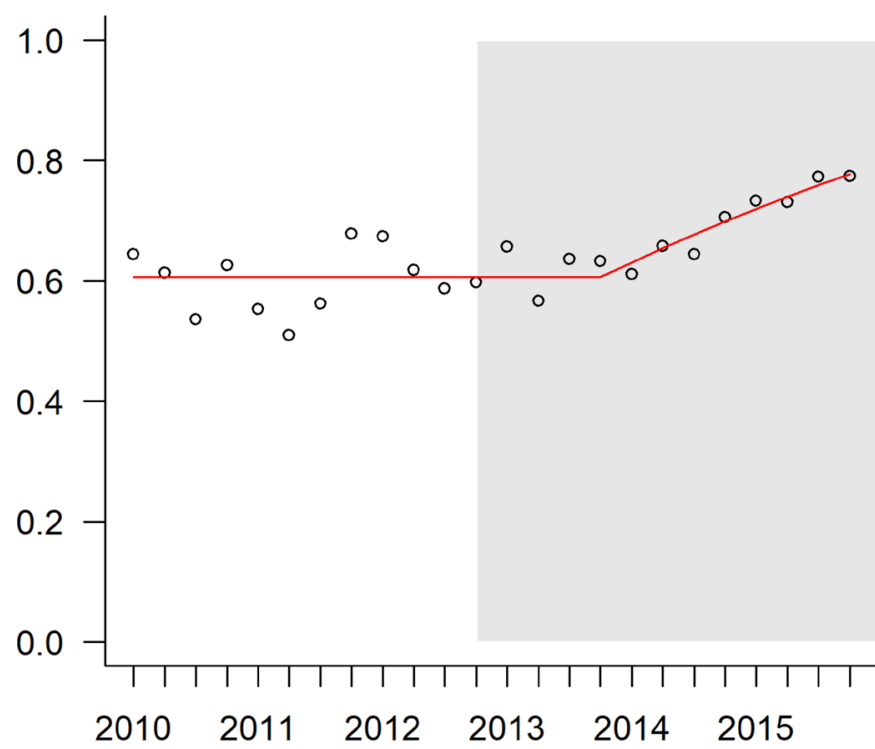

Time (Quarter)

Figure 2 Observed proportion of patients persisting with DAPT for at least 12 months at each quarter and the interrupted time series model fitted after setting a 1 year lag period from publication to implementation of guidelines. DAPT, dual antiplatelet therapy.

procedure, taking prasugrel instead of clopidogrel and a recommendation of DAPT for a longer period at discharge from the PCI hospital. Autocorrelation was not significant. Guideline implementation had a positive effect on persistence: a $20 \%$ increase in the odds of 12-month persistence each quarter after a lag of 1 year since publication. The effect of drug-eluting stents was attenuated with time (OR for interaction: $0.96 ; 95 \%$ CI 0.94 to 0.97 ) while the effect of prescription was attenuated with time after guideline implementation (OR for the interaction 0.86 , $95 \%$ CI 0.79 to 0.94 for a recommendation of $\geq 12$ months and $0.88,95 \%$ CI 0.81 to 0.97 for an unknown recommendation). The effect of implantation of drug-eluting stents and type of recommendation also varied between hospitals (significant random slopes).

Results of sensitivity analyses, excluding patients with ischaemic or haemorrhagic events during follow-up, or excluding patients who were transferred to another centre after PCI were similar to the main analysis (online supplementary table $3 \mathrm{~S}$ ).

The interaction between drug-eluting stents and time can be seen in figure 3A. Because 12-month persistence increased with time in patients without drug-eluting stents, the effect of type of stent is attenuated with time. The interaction of the recommendation pattern with time and guideline implementation can be seen in figure 3B: 12-month persistence increased with time mainly in the subgroups with shorter time specification in the discharge report and also in patients without a specific recommendation, but this increase started after guideline implementation (1 year after publication). Figure $3 \mathrm{C}$ shows a substantial reduction in the variability between centres 
Table 3 Factors associated with a persistence of at least 12 months as assessed with interrupted time series logistic regression model

\begin{tabular}{llll}
\hline Fixed effects & OR & $\mathbf{9 5 \%}$ Cl & P value \\
\hline $\begin{array}{l}\text { Drug-eluting stent } \\
\text { No of stents }\end{array}$ & 1.90 & 1.50 to 2.40 & $<0.001$ \\
$\begin{array}{l}\text { Antiplatelet agent } \\
\text { at discharge (Ref. } \\
\text { clopidogrel) }\end{array}$ & & 1.13 to 1.32 & $<0.001$ \\
\hline \multicolumn{1}{l}{$\begin{array}{l}\text { Prasugrel } \\
\quad \text { Ticagrelor }\end{array}$} & 1.59 & 0.88 to 1.26 & $<0.001$ \\
\hline
\end{tabular}

Recommendation at

$\mathrm{PCl}$ hospital discharge

(Ref. 1 month)

\begin{tabular}{|c|c|c|c|}
\hline$<12$ months & 1.67 & 0.89 to 3.14 & 0.110 \\
\hline$\geq 12$ months & 5.76 & 3.26 to 10.2 & $<0.001$ \\
\hline Unknown & 2.25 & 0.84 to 6.01 & 0.107 \\
\hline Hypercholesterolaemia & 1.19 & 1.08 to 1.31 & $<0.001$ \\
\hline $\begin{array}{l}\text { Previous by-pass } \\
\text { surgery }\end{array}$ & 1.85 & 1.09 to 3.14 & 0.023 \\
\hline $\begin{array}{l}\text { Two or more treated } \\
\text { vessels }\end{array}$ & 1.21 & 1.10 to 1.33 & $<0.001$ \\
\hline $\begin{array}{l}\text { Drug-eluting stent * } \\
\text { time (quarter) }\end{array}$ & 0.96 & 0.94 to 0.97 & $<0.001$ \\
\hline $\begin{array}{l}\text { Guideline } \\
\text { implementation }\end{array}$ & 1.20 & 1.11 to 1.30 & $<0.001$ \\
\hline \multicolumn{4}{|l|}{$\begin{array}{l}\text { Recommendation at } \\
\text { PCI hospital discharge } \\
\text { (Ref. } 1 \text { month)* time } \\
\text { (quarter) * guideline } \\
\text { implementation }\end{array}$} \\
\hline$<12$ months & 0.90 & 0.79 to 1.04 & 0.144 \\
\hline$\geq 12$ months & 0.86 & 0.79 to 0.94 & $<0.001$ \\
\hline Unknown & 0.88 & 0.81 to 0.97 & 0.007 \\
\hline Random effects & \multicolumn{2}{|c|}{ Variance } & \\
\hline Random-intercept & \multicolumn{2}{|c|}{0.46} & to 1.53 \\
\hline
\end{tabular}

Random-slopes

\begin{tabular}{|c|c|c|}
\hline $\begin{array}{l}\text { Recommendation at PCI } \\
\text { hospital discharge (Ref. } \\
1 \text { month) }\end{array}$ & & \\
\hline$<12$ months & 0.37 & 0.17 to 1.23 \\
\hline$\geq 12$ months & 0.39 & 0.19 to 1.31 \\
\hline Unknown & 1.97 & 0.93 to 6.58 \\
\hline Drug-eluting stent & 0.10 & 0.05 to 0.33 \\
\hline $\begin{array}{l}\text { Adjusted Intracalss } \\
\text { Correlation Coefficient }\end{array}$ & 0.085 & \\
\hline
\end{tabular}

$\mathrm{PCl}$, percutaneous coronary intervention.

mainly due to an increase in the proportion of 12-month persistence in patients attended in centres where the initial proportion was lower (significant random intercept and slopes).
A

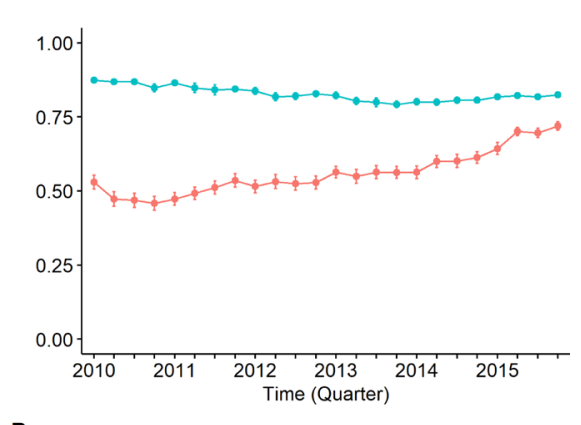

B
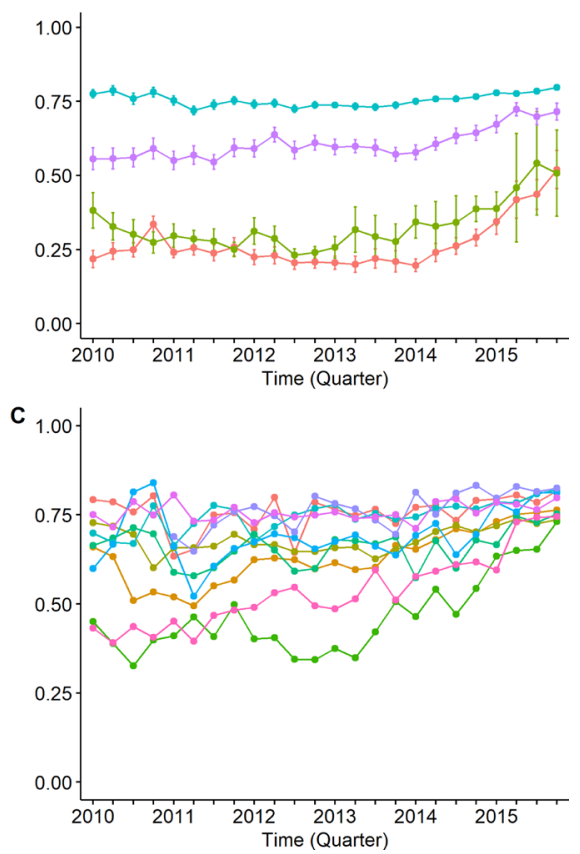

Figure 3 Temporal trend of interhospital variability in 12-month DAPT recommendation at the PCI hospital, measured as the percentage of variance explained by the hospital level (intraclass correlation and 95\% Cl). Predicted probabilities of 12-month persistence by $(A)$ drug-eluting stent, $(B)$ recommendation pattern and $(C)$ centre, over time. DAPT, dual antiplatelet therapy; $\mathrm{PCl}$, percutaneous coronary intervention.

\section{DISCUSSION}

According to published guidelines, all STEACS patients undergoing PCI without contraindication should be kept on DAPT for at least 12 months unless an event occurs that precludes continuing with this treatment. In this observational region-wide study, we have found an increase in the proportion of patients on-DAPT at 12 months from $58 \%$ to $73 \%$ in the period from 2010 to 2015 , with an accelerated rate starting in the fourth quarter of 2013, 1 year after the publication of European guidelines.

We also found a high variability between hospitals in the adherence to guidelines when recommending DAPT for at least 12 months which leads to substantial differences between hospitals in the rate of patients persisting with the recommended DAPT. The progressive increase 
in the overall rate of 12-month persistence was accompanied by a substantial reduction of interhospital variability.

Likelihood of patients persisting with DAPT for 1 year is strongly related to the instructions given at the PCI hospital discharge, as we observed a lower rate of 12-month persistence in patients receiving a discharge DAPT recommendation for $<12$ months. Although a causal direct relationship between the established recommendation in the more specialised setting and the final prescription at the primary care setting cannot be stated on the basis of observational data, this finding suggests that prescribing physicians strongly rely on the first recommendation specified at the discharge report in the PCI hospital. Therefore, hospital cardiologists should be kept aware of their impact and encouraged to be clear and specific enough when providing DAPT time recommendations in the discharge report form.

The recommendation in clinical guidelines of DAPT for at least 12 months following STEACS ${ }^{12}$ was based on the duration of follow-up of randomised clinical trials designed for other purposes ${ }^{11-13}$ and, although a 12-month treatment seemed reasonable, ${ }^{14}$ no randomised studies had been performed within the study period aimed specifically at comparing 12-month DAPT with shorter periods in STEACS patients receiving PCI and thus this recommendation might well be seen as somehow arbitrary by some prescribers.

In 2015, the need for long-term DAPT was reinforced by the recommendation of extended DAPT beyond 12 months in patients with ACS receiving drug-eluting stents, ${ }^{15-17}$ but still safety concerns might induce some prescribers to be reluctant to prolong DAPT, especially in patients with higher complexity. ${ }^{18}$ Safety concerns might also explain the high proportion of discharge reports with non-specified DAPT period, which deserved special attention in our analyses. Cardiologists might be reluctant to prescribe a specific duration of DAPT maybe fearing about the emergency of events that increase the haemorrhagic risk at some point after discharge, thus relying on the follow-up that will be made at the ambulatory setting. Our results showing a high degree of persistence for patients without a specification of DAPT time point out to the fact that this decision is not necessarily 'incorrect', and that health providers coming later in the process of care are probably doing their job.

We might wonder whether the observed high variability between hospitals in the instructions provided about DAPT duration actually reflects suboptimal quality of care or confusion in the interpretation of international guidelines. In fact, although 2012 European Society of Cardiology guidelines state that DAPT must be continued for 12 months after STEACS with a class of recommendation I, the level of evidence was established as C. ${ }^{1}$ Thus, there was general agreement that a minimum of 12 months of DAPT is likely to be beneficial but based only on a consensus of experts or observational studies. Moreover, it is literally stated that the given recommendation on DAPT duration should be "with a strict minimum of 1 month for patients receiving BMS and 6 months for patients receiving DES', with class IC and IIb, respectively. These messages, which ultimately reflected the lack of clinical trials aimed to answer the specific question about DAPT duration, could have induced a perception of arbitrariness leading to variability in clinical practice.

In fact, the optimal duration of DAPT has not yet been totally established in more contemporary clinical trials. The most recent randomised clinical trial conducted in patients with STEACS aimed to assess the question of 12-month vs a 6-month DAPT duration, showed that 6-month DAPT duration after primary PCI was non-inferior to 12-month duration to prevent major cardiovascular events. ${ }^{19}$ In another trial in the context of ACS, 12 months or longer DAPT duration versus 6 months was not associated with lower major cardiovascular events and total mortality. ${ }^{20}$

Regardless the level of the evidence, one would expect that a class I recommendation should be uniformly followed by clinicians. Moreover, as patient characteristics did not substantially differed across hospitals, we should expect a lower variability between hospitals. A large variation in individual country practices concerning the pattern of DAPT duration after ACS has been described, suggesting that local systems are strong drivers of DAPT duration. ${ }^{21}$ These findings may imply that there is still room for improvement in the quality of care of STEACS patients and that quality improvement programmes, whose efficacy and cost-effectiveness are still under evaluation, could be useful to reduce variability in clinical practice. ${ }^{22}$ This is of prime importance in the context of the prescription of DAPT duration after ACS in which the clinician-driven variability in prescription patterns adds to the different levels patients' adherence. ${ }^{21}$

Higher atherosclerotic burden and increased ischaemic risk was associated to better persistence with DAPT. The need for 12-month DAPT schedules in patients treated with drug-eluting stents is clearly perceived by physicians but the magnitude of this association varies largely between hospitals. This means that, even in clear indications, there are different levels of adoption of emerging clinical recommendations in hospitals belonging to the same AMI network.

It is also apparent from our data that the speed of adoption of clinical guidelines is different among hospitals and that an acceptable and generalised level of adherence is only reached after 2 years of implementation. Similar trends have been found in other contexts and earlier periods $^{23-28}$ reporting DAPT use between $60 \%$ and $80 \%$ at discharge and between $25 \%$ and $75 \%$ at 1 year. In this sense, together with other quality improvement initiatives, the use of population-based registries to provide audit and feedback could be useful to promote quicker and smoother adoption of clinical practice guidelines. ${ }^{29}$

There are a number of assumptions that might be questionable: a number of factors have been described to contribute to underprescription. ${ }^{30}$ The complete process of care and the definite prescription at the ambulatory 
setting is poorly known for individual patients and has not been considered in this study. Changes in treatment prescription might be justified by the patients' varying conditions during follow-up. We assume that hospital recommendation influences final prescription, and consequently, final adherence to guidelines, but it can also be that both 'prescribers' facing the same patient share the same criteria for prescription. That is, the hospital cardiologist might have decided to recommend DAPT for a shorter period to an elderly patient with other comorbidities and suboptimal quality of life due to mild digestive symptoms, even if her objective bleeding risk is not high; similarly, the primary physician or the cardiologist at the primary care setting might have also decided to be less aggressive for the same reasons, even without being influenced by the recommendation of the first prescriber. This would probably explain a large amount of the strong relationship between hospital recommendation and pharmacy dispensation. Moreover, although effects were adjusted for patient characteristics and vascular events during follow-up, there might be other unmeasured reasons for deciding on a shorter DAPT period facing an individual patient.

In addition, the recommendation at PCI hospital discharge may not coincide with the final hospital prescription in patients derived to another reference hospital after PCI. However, results of sensitivity analyses excluding these patients did not differ substantially from the results of the main analyses.

The study was aimed to ascertain influence of guidelines on hospital recommendation and its impact on patients' persistence with DAPT. The impact of persistence on clinically relevant results will be assessed in another article. Similarly, the study was not specifically aimed at a deep assessment of determinants of adherence. This requires a detailed examination of the social context and a detailed assessment of individual psychological factors. ${ }^{31}$

\section{CONCLUSION}

The study shows that 12-month DAPT persistence in revascularised patients with STEACS in Catalonia (Spain) has substantially increased between years 2010 and 2015 especially since 1 year after the publication of European guidelines in 2012. Guideline implementation was also followed by a substantial decrease in variability between centres. We have shown that instructions given at the PCI hospital discharge are strongly associated with persistence. Thus, establishing common and rational prescribing criteria between hospitals in the STEACS network may favour patients persistence with scheduled prescriptions and also reduce variability in clinicians' practices.

\section{Author affiliations}

${ }^{1}$ Cardiology Department, Vall d'Hebron University Hospital and Research Institute, Universitat Autònoma de Barcelona, Barcelona, Spain

${ }^{2}$ Servei Català de la Salut, Generalitat de Catalunya, Barcelona, Spain

${ }^{3}$ Departament de Salut, Generalitat de Catalunya, Barcelona, Spain
${ }^{4}$ Cardiology Department, Hospital del Mar, and Heart Diseases Biomedical Research Group and IMIM (Hospital del Mar Medical Research Institute), Faculty of Medicine, Universitat Autonoma de Barcelona, Barcelona, Spain

${ }^{5}$ Cardiology Department, Hospital Universitari de Tarragona Joan XXIII, IISPV, Universidad Rovira Virgili, Tarragona, Spain

${ }^{6}$ Cardiology Department, Hospital Germans Trias i Pujol, Badalona, Spain

${ }^{7}$ Cardiology Department, Hospital Josep Trueta, Girona, Spain

${ }^{8}$ Cardiology Department, Hospital Mútua de Terrassa, Barcelona, Spain

${ }^{9}$ Cardiology Department, Hospital Arnau de Vilanova, Lleida, Spain

${ }^{10}$ Cardiology Department, Hospital de la Santa Creu i Sant Pau, Barcelona, Spain

${ }^{11}$ Cardiology Department, Hospital de Bellvitge, Barcelona, Spain

${ }^{12}$ Clinical Epidemiology Unit, Hospital Universitario de Cruces. Biocruces Bizkaia Health Research Institute, Bilbao, Spain

${ }^{13}$ Institut Clínic Cardio vascular (ICCV), Hospital Clínic de Barcelona, Barcelona, Spain

${ }^{15}$ Centro de Investigación Biomédica en Red en Epidemiología y Salud Pública CIBERESP, The Spanish Health Institute (ISCIII), Spain

${ }^{16}$ Centro de Investigación Biomédica en Red para Enfermedades Cardiovasculares CIBERCV, Spanish Health Institute (ISCIII), Spain

Collaborators The Codi IAM Registry Investigators (listed below) contribute to the functioning of the Codi IAM and to data acquisition for the Codi IAM Registry: C Carvajal, P Martínez, RM Lidón, J Bañeras (Hospital Universitari de la Vall d’Hebrón, Barcelona), J Garcia-Picart (Hospital de la Santa Creu i Sant Pau, Barcelona), M Massotti, G Jiménez, M Hernández, A Regueiro (Hospital Clinic, Barcelona), J Basaganyas, P Loma, M Cardenas, E Badosa, A Fageda (Hospital Josep Trueta, Girona) A Ariza, C García-Amigó, A Cequier, A Gómez-Hospital, G Marín, J Maristany, V Montoya (Hospital Universitari de Bellvitge, Hospitalet), C Labata, J Mauri, E Fernández-Nofrerias, X Carrillo, C Garcia-Garcia, C Oliete (Hospital Universitari Germans Trias i Pujol, Badalona), A Bardaji, G Bonet-Pineda, S Rojas (Hospital Joan XXIII, Tarragona). Juan F Muñoz, F Padilla, S Homs (Hospital Mútua de Terrassa, Terrassa), B Baquerizo, L Recasens, H Tizon-Marcos (Hospital de Mar IMAS, Barcelona), A Bosch Gaya, F Worner, L Barta, M Agustí, A Gené (Hospital Arnau de Vilanova, LLeida), X Jimenez, A Mora (Sistema d'Emergencies Mèdiques SEM SA, Barcelona), MT Faixedas, J Jiménez, A Rosas (Health Department, Generalitat de Catalunya).

Contributors IF-G, ARi and JRM conceived and designed the study. ARi, JRM and MTF participated in the acquisition and analysis of data. HT-M, SR, CL, MC, SH, CT-Q, JG-P, JAG-H and MM were responsible for data acquisition in their respective hospitals. ARi, IF-G, JRM, G0, ARo, JIP, JM and DGD were involved in the interpretation of results. ARi and IF-G wrote the manuscript and all other authors revised it critically and approved its final version.

Funding The study was supported by Instituto de Salud Carlos III grand number Pl13/00399 and the Fundació la Marató de TV3 grand number 430/U/2015. The funders did not have any role in the study design and development.

Competing interests None declared.

Patient consent for publication Not required.

Ethics approval The study obtained ethics approval from the Vall d'Hebron Clinical Research Ethics Committee (EPA(AG)7/2014(3989)).

Provenance and peer review Not commissioned; externally peer reviewed.

Data sharing statement The study is based on clinical and administrative data that belong to the Government administration and is not subject to data sharing.

Open access This is an open access article distributed in accordance with the Creative Commons Attribution Non Commercial (CC BY-NC 4.0) license, which permits others to distribute, remix, adapt, build upon this work non-commercially, and license their derivative works on different terms, provided the original work is properly cited, appropriate credit is given, any changes made indicated, and the use is non-commercial. See: http://creativecommons.org/licenses/by-nc/4.0/.

\section{REFERENCES}

1. Steg PG, James SK, Atar D, et al. ESC Guidelines for the management of acute myocardial infarction in patients presenting with ST-segment elevation: The Task Force on the management of ST-segment elevation acute myocardial infarction of the European Society of Cardiology (ESC). Eur Heart J 2012;33:2569-619. 
2. O'Gara PT, Kushner FG, Ascheim DD, et al. 2013 ACCF/AHA Guideline for the Management of ST-Elevation Myocardial Infarction: A Report of the American College of Cardiology Foundation/ American Heart Association Task Force on Practice Guidelines. Circulation 2013;2013:e362-425.

3. Osterberg L, Blaschke T. Adherence to medication. N Engl J Med 2005;353:487-97.

4. Carrillo X, Fernandez-Nofrerias E, Rodriguez-Leor O, et al. Early ST elevation myocardial infarction in non-capable percutaneous coronary intervention centres: in situ fibrinolysis vs. percutaneous coronary intervention transfer. Eur Heart J 2016;37:1034-40.

5. Regueiro A, Bosch J, Martín-Yuste V, et al. Cost-effectiveness of a European ST-segment elevation myocardial infarction network: results from the Catalan Codi Infart network. BMJ Open 2015;5:e009148.

6. Swieczkowski D, Mogielnicki M, Cwalina N, et al. Medication adherence in patients after percutaneous coronary intervention due to acute myocardial infarction: From research to clinical implications. Cardiol J 2016;23:483-90.

7. Gislason GH, Rasmussen JN, Abildstrøm SZ, et al. Long-term compliance with beta-blockers, angiotensin-converting enzyme inhibitors, and statins after acute myocardial infarction. Eur Heart $J$ 2006;27:1153-8.

8. Kontopantelis E, Doran T, Springate DA, et al. Regression based quasi-experimental approach when randomisation is not an option: interrupted time series analysis. BMJ 2015;350:h2750.

9. Bernal JL, Cummins S, Gasparrini A. Interrupted time series regression for the evaluation of public health interventions: a tutorial. Int J Epidemiol 2017;46:348-355.

10. Yeh RW, Secemsky EA, Kereiakes DJ, et al. Development and validation of a prediction rule for benefit and harm of dual antiplatelet therapy beyond 1 year after percutaneous coronary intervention. JAMA 2016;315:1735.

11. Yusuf S, Zhao F, Mehta SR, et al. Effects of clopidogrel in addition to aspirin in patients with acute coronary syndromes without STsegment elevation. N Engl J Med 2001;345:494-502.

12. Wiviott SD, Braunwald E, McCabe CH, et al. Prasugrel versus clopidogrel in patients with acute coronary syndromes. N Engl J Med 2007;357:2001-15.

13. Wallentin L, Becker RC, Budaj A, et al. Ticagrelor versus clopidogrel in patients with acute coronary syndromes. $N$ Engl J Med 2009;361:1045-57.

14. Eisenstein EL, Anstrom KJ, Kong DF, et al. Clopidogrel use and longterm clinical outcomes after drug-eluting stent implantation. JAMA 2007;297:159.

15. Bonaca MP, Bhatt DL, Cohen M, et al. Long-term use of ticagrelor in patients with prior myocardial infarction. $N$ Engl $J$ Med 2015;372:1791-800.

16. Mauri L, Kereiakes DJ, Yeh RW, et al. Twelve or 30 months of dual antiplatelet therapy after drug-eluting stents. $N$ Engl J Med 2014;371:2155-66.

17. Levine GN, Bates ER, Bittl JA, et al. 2016 ACC/AHA Guideline Focused Update on Duration of Dual Antiplatelet Therapy in Patients With Coronary Artery Disease: A Report of the American College of Cardiology/American Heart Association Task Force on Clinical Practice Guidelines. J Am Coll Cardiol 2016;68:1082-115.
18. Tinetti ME, Bogardus ST, Agostini JV. Potential pitfalls of diseasespecific guidelines for patients with multiple conditions. $N$ Engl $J$ Med 2004;351:2870-4.

19. Kedhi E, Fabris E, van der Ent M, et al. Six months versus 12 months dual antiplatelet therapy after drug-eluting stent implantation in ST-elevation myocardial infarction (DAPT-STEMI): randomised, multicentre, non-inferiority trial. BMJ 2018;363:k3793.

20. Hahn JY, Song YB, Oh JH, et al. 6-month versus 12-month or longer dual antiplatelet therapy after percutaneous coronary intervention in patients with acute coronary syndrome (SMARTDATE): a randomised, open-label, non-inferiority trial. Lancet 2018;391:1274-84

21. Bueno H, Pocock S, Danchin N, et al. International patterns of dual antiplatelet therapy duration after acute coronary syndromes. Heart 2017;103:132-8.

22. Flather MD, Babalis $\mathrm{D}$, Booth $\mathrm{J}$, et al. Cluster-randomized trial to evaluate the effects of a quality improvement program on management of non-ST-elevation acute coronary syndromes: the European Quality Improvement Programme for Acute Coronary Syndromes (EQUIP-ACS). Am Heart J 2011;162:700-7.

23. Czarny MJ, Nathan AS, Yeh RW, et al. Adherence to dual antiplatelet therapy after coronary stenting: a systematic review. Clin Cardiol 2014;37:505-13.

24. Green A, Pottegård A, Broe A, et al. Initiation and persistence with dual antiplatelet therapy after acute myocardial infarction: a Danish nationwide population-based cohort study. BMJ Open 2016;6:e010880.

25. Anastasius M, Lau JK, Hyun K, et al. The underutilisation of dual antiplatelet therapy in acute coronary syndrome. Int $J$ Cardiol 2017; 240:30-6.

26. Prami T, Khanfir H, Deleskog A, et al. Clinical factors associated with initiation of and persistence with ADP receptor-inhibiting oral antiplatelet treatment after acute coronary syndrome: a nationwide cohort study from Finland. BMJ Open 2016;6:e012604.

27. Varenhorst C, Jensevik K, Jernberg T, et al. Duration of dual antiplatelet treatment

with clopidogrel and aspirin in patients with acute coronary syndrome. Eur Heart $J$ 2014:35:969-78.

28. Chung SC, Sundström J, Gale CP, et al. Comparison of hospital variation in acute myocardial infarction care and outcome between Sweden and United Kingdom: population based cohort study using nationwide clinical registries. BMJ 2015;351:h3913.

29. Eisenstein EL, Wojdyla D, Anstrom KJ, et al. Evaluating the impact of public health notification: Duke clopidogrel experience. Circ Cardiovasc Qual Outcomes 2012;5:767-74.

30. Cabana MD, Rand CS, Powe NR, et al. Why don't physicians follow clinical practice guidelines? A framework for improvement. JAMA 1999.65.

31. Ferreira-González I, Marsal JR, Ribera A, et al. Background, incidence, and predictors of antiplatelet therapy discontinuation during the first year after drug-eluting stent implantation. Circulation 2010;122:1017-25 